\title{
Coupled Simulation of Heat Transfer and Phase Transformation in Continuous Casting of Steel
}

\author{
Jyrki MIETTINEN, Seppo LOUHENKILPI and Lauri HOLAPPA
}

Laboratory of Metallurgy, Helsinki University of Technology, Vuorimiehentie 2, 02150 Espoo, Finland.

(Received on May 13, 1996; accepted in final form on July 15, 1996)

\begin{abstract}
A computer software package has been developed to simulate temperature, shell growth and phase transformations in continuous casting of steel. The package includes two earlier developed models, a heat transfer model and a thermodynamic-kinetic phase transformation model. The phase transformation model takes into account the effect of alloying and cooling on the phase transformation temperatures and on this basis, on important, solidification related thermophysical properties, enthalpy and thermal conductivity, generated by the model. Hence, while affecting these properties, the phase transformations have a special influence on the heat transfer in the strand. The output of these coupled calculations are temperature distribution, phase distribution (liquid, delta ferrite and austenite, and approximately, proeutectoid ferrite, pearlite, bainite and martensite) and volume distribution through the strand, and also, hardness distribution on the cross-section of the strand at room temperature. Characteristics of the coupled model and some results of calculations are presented.
\end{abstract}

KEY WORDS: simulation; heat transfer; phase transformation; continuous casting; steel.

\section{Introduction}

Applications of heat transfer analysis to continuous casting are numerous in the literature and give directly pertinent data like surface temperature and shell thickness. The heat transfer models are currently enhanced in several directions; one of these not very far developed includes the prediction of microstructure in continuous casting modeling. The heat transfer and microstructural models should be coupled, because the kinetics of phase transformations depends on cooling rate, and the thermophysical material properties needed in heat transfer calculations are related to the phases formed.

This paper presents a computer software package for the prediction of temperature distribution and some microstructural features such as phase fractions throughout a strand in continuous casting. The package includes two earlier developed models, a heat transfer mode ${ }^{1)}$ and a thermodynamic-kinetic phase transformation model. ${ }^{2,3}$ The latter model also calculates the thermophysical material properties of steels, ${ }^{4,5)}$ taking into account the temperature, the cooling rate and the steel composition. Characteristics of the models and some results are presented.

\section{Mathematical Models and Algorithms}

\subsection{Heat Transfer Model}

The temperature field in the strand is described by the heat conduction equation with phase change. The model $^{1)}$ calculates the temperature field in the twodimensional cross-section of the strand on its way through the casting machine as a function of casting parameters and steel grade. The heat conduction in the withdrawal direction is comparatively small and is neglected. The equation takes the form:

$$
\rho \frac{\partial H}{\partial t}=\frac{\partial}{\partial x}\left(k \frac{\partial T}{\partial x}\right)+\frac{\partial}{\partial y}\left(k \frac{\partial T}{\partial y}\right)
$$

The necessary material data are the density, $\rho$, the enthalpy, $H$, and the thermal conductivity, $k$. Now, the enthalpy also includes the phase change heats. The numerical solution is obtained using the finite element method in space and the implicit finite difference method in time.

\subsection{Phase Transformation Model}

The solidification simulation of the phase transformation model $^{2)}$ is made in one volume element set on the side of a dendrite arm; as a result of these calculations, one gets the fractions and the compositions of liquid (L), ferrite $(\delta)$ and austenite $(\gamma)$ as a function of the decreasing temperature. The model solves the thermodynamic equilibrium at the interface of two solution phases, $\delta$ and $\mathrm{L}, \gamma$ and $\mathrm{L}$, and $\gamma$ and $\delta$, using the chemical-potentialequality equations:

$$
\begin{array}{r}
\mu_{i}^{\phi 1}\left(T, x_{1}^{\phi 1}, \cdots,\right. \\
\left.x_{n}^{\phi 1}\right)=\mu_{i}^{\phi 2}\left(T, x_{1}^{\phi 2}, \cdots, x_{n}^{\phi 2}\right) \\
(i=1, \cdots, n)
\end{array}
$$

and the phase interface movement is simulated by means of modified interfacial material balance equations of solutes:

$$
\begin{aligned}
\Delta f^{\phi 1 / \phi 2} & \left(x_{i}^{\phi 2}-x_{i}^{\phi 1}\right)=S_{i}^{\phi 2}\left(T, x_{i}^{\phi 2}, D_{i}^{\phi 2}\right) \\
& -S_{i}^{\phi 1}\left(T, x_{i}^{\phi 1}, D_{i}^{\phi 1}\right) \quad(i=2, \cdots, n)
\end{aligned}
$$

In these equations, $\mu_{i}^{\phi}$ is the chemical potential of component $i$ in phase $\phi, x_{i}^{\phi}$ is the mole fraction of the component in phase $\phi, T$ is temperature, $n$ is the number of components in the alloy, $\Delta f^{\phi 1 / \phi 2}$ is the fractional 
movement of the $\phi 1 / \phi 2$ interface, $S_{i}^{\phi}$ is a parameter describing the amount of solute $i$ entering or leaving the interface, and $D_{i}^{\phi}$ is the diffusion coefficient of solute $i$ in phase $\phi$. Parameters $\mu_{i}^{\phi}$ based on the use of the substitutional solution model and parameters $S_{i}^{\phi}$ involving Fick's first law of diffusion have been defined in references ${ }^{6)}$ and, ${ }^{2)}$ respectively. The calculations are made stepwise and in each step, Eqs. (2) and (3) are solved simultaneously for each interface present. After solving these equations at a certain step, the solute diffusion in solid is simulated with a special finite difference application of Fick's second law. ${ }^{2}$ )

Recently, the phase transformation model of solidification has been extended by another phase transformation model simulating the decomposition of austenite to various structures containing ferrite and cementite. ${ }^{3)}$ The austenite decomposition model applies the substitutional solution model using a para-equilibrium condition ${ }^{7,8}$ ) during the cooling process, an analytical carbon diffusion model simulating the movement of the $\alpha / \gamma$ interface in spherical grains ${ }^{9)}$ and special regression formulas based on the German and the British CCT experiments, ${ }^{10-12}$ ) taking into account the effect solutes $\mathrm{C}, \mathrm{Si}, \mathrm{Mn}, \mathrm{Cr}, \mathrm{Mo}$, $\mathrm{Ni}$, cooling rate and austenite grain size. The effect of stress on the transformation kinetics, however, has been ignored. The calculations of the new, extended phase transformation model have been compared with numerous solidification and CCT experiments showing a good correlation between the results. ${ }^{13)}$

Finally, special algorithms have been developed ${ }^{4)}$ for the calculation of important solidification-related thermophysical material properties, enthalpy, density and thermal conductivity needed in heat-transfer calculations taking into account the discontinuities caused by phase transformations. The data for these calculations are shown in references. ${ }^{5,6}$ )

\subsection{Coupling of Phase Transformation and Thermal Calculations}

The models of the work have been coupled as follows:

1) Assume a cooling rate for solidification and for austenite decomposition.

2) Calculate the material properties for the heat transfer model using the phase transformation model and the assumed cooling rates.

3) Calculate the temperature distribution and the cooling rates of each node using the heat transfer model.

4) If the calculated cooling rates on average match the assumed cooling rates, go to step 5). Otherwise, go back to step 1).

5) Calculate the microstructural evolutions through the strand with the phase transformation model. This is done separately for each node point in the finite element mesh using the nodal steel composition and the nodal cooling rates.

The calculation procedure is not yet fully coupled, because the material properties for the heat transfer model are calculated by mean solidification and cooling rates of the strand. Normally, the cooling rates vary at different points in the strand. To be precise, this should be taken into account when solving the heat transfer equations.

\subsection{Estimation of Microstructure Data}

The phase transformation model applies special microstructure data as input data for the calculations. The secondary dendrite arm thickness of solidification is predicted as $d_{2}=150 \cdot \dot{T}^{-0.385}$ for low-alloyed steels ${ }^{15}$ ) and as $d_{2}=68 \cdot \dot{T}^{-0.45}$ for stainless steels. ${ }^{16)}$ Here, $d_{2}$ is in $\mu \mathrm{m}$ and $\dot{T}$ is the cooling rate in ${ }^{\circ} \mathrm{C} / \mathrm{s}$. The austenite grain size of an as-cast structure is roughly estimated as $d_{\text {GRAIN }}=21 \cdot T^{\gamma}-3152 \cdot[\exp \dot{T} /(1+\exp \dot{T})]-25088$ based on the work of Yasumoto et al. ${ }^{17)} T^{\gamma}$ is the highest temperature (in ${ }^{\circ} \mathrm{C}$ ) of a totally austenitic structure and $\dot{T}$ is the cooling rate of solidification in ${ }^{\circ} \mathrm{C} / \mathrm{s}$. The validity of this equation, however, has not been checked beyond the cooling rate range 0.1 to $1.5^{\circ} \mathrm{C}$ studied by Yasumoto et al. $^{17)}$

\subsection{Incorporating a Macrosegregation Profile}

Normally, the austenite decomposition model applies the steel composition (either the nominal or the interdendritic composition) in the calculations. However, the macrosegregation profiles of solutes, if known, can also be used as input data. Depending on the degree of macrosegregation, one may then get different phases in different parts of the strand causing changes in volume and hardness through the strand.

\subsection{Calculation of Volume Changes}

Due to the different densities of ferrite and austenite, certain volume changes are expected to occur in the strand during the austenite decomposition process. The rate of these volume changes depends on the rate of the decomposition process influenced by the steel grade, the cooling conditions and the microstructure. Knowing the density function $\rho(T)$ obtained with the phase transformation model and the temperature distribution $T(x, z)$ obtained with the heat transfer model, the volume distribution of the strand can be expressed as $V(T(x, z))=1 / \rho(T(x, z))$. Here $V$ is given in $\mathrm{cm}^{3} / \mathrm{g}, x$ is the distance from the strand surface and $z$ is the distance from the meniscus.

\subsection{Calculation of Hardness at Room Temperature}

The British Steel Corporation ${ }^{12}$ ) has given the following functions for the prediction of hardness (at room temperature) in various structures of low-alloyed steels: $H V^{\mathrm{M}}=127+949 \mathrm{C}+27 \mathrm{Si}+11 \mathrm{Mn}+16 \mathrm{Cr}+8 \mathrm{Ni}+$ $21 \cdot \log (\dot{T}), \quad H V^{\mathrm{B}}=-323+185 \mathrm{C}+330 \mathrm{Si}+153 \mathrm{Mn}+$ $144 \mathrm{Cr}+191 \mathrm{Mo}+65 \mathrm{Ni}+(89+53 \mathrm{C}-55 \mathrm{Si}-22 \mathrm{Mn}-$ $20 \mathrm{Cr}-33 \mathrm{Mo}-10 \mathrm{Ni}) \cdot \log (\dot{T})$ and $H V^{\mathrm{F}+\mathrm{P}}=42+223 \mathrm{C}+$ $+53 \mathrm{Si}+30 \mathrm{Mn}+7 \mathrm{Cr}+19 \mathrm{Mo}+12.6 \mathrm{Ni}+(10-19 \mathrm{Si}+$ $8 \mathrm{Cr}+4 \mathrm{Ni}) \cdot \log (\dot{T})$, where $\dot{T}$ is the cooling rate in ${ }^{\circ} \mathrm{C} / \mathrm{hr}$. Now, knowing the fractions of martensite $\left(f^{\mathrm{M}}\right)$, bainite $\left(f^{\mathrm{B}}\right)$, ferrite $\left(f^{\mathrm{F}}\right)$ and pearlite $\left(f^{\mathbf{P}}\right)$ through the strand, calculated with the austenite decomposition model, one can estimate the hardness profile of the final structure as $H V=f^{\mathrm{M}} \cdot H V^{\mathrm{M}}+f^{\mathrm{B}} \cdot H V^{\mathrm{B}}+\left(f^{\mathrm{F}}+f^{\mathrm{P}}\right) \cdot H V^{\mathrm{F}+\mathrm{P}}$.

\section{Calculation Examples}

This section shows two calculation examples for the 
steels of Table 1.

\subsection{Prediction of Phase Regions and Thermal Contrac- tion during Solidification of Stainless Steel Slabs}

Figures 1 and 2 show the calculated phase regions of solidification and the related thermal contraction for continuously cast AISI 304 and AISI 316 slabs. Assuming that solid fraction 0.80 can be related to the zero strength point of the steel, where dendrite arms have their first contact with each other and the liquid feeding becomes insufficient to totally compensate the shrinkage, one can approximate the mushy zone contraction as $\beta_{\text {Mus }}(\%)$ $=100\left(1-\rho_{80 \%} / \rho_{\mathrm{SOL}}\right)$. Here, $\rho_{80 \%}$ and $\rho_{\mathrm{SOL}}$ are the densities corresponding to the temperature of 0.80 solid fraction and the solidus temperature. For AISI 304, this yielded $\beta_{\text {MUS }}=1.35$ and for AISI 316, it yielded $\beta_{\text {MUS }}=0.91$. The higher mushy zone contraction of AISI 304 can be explained by the greater amount of ferrite transformed away in the peritectic transformation region: in AISI 304, the ferrite fraction decreased from 0.80 to 0.45 (with a total fraction of 0.35 ) whereas in AISI 316 , it decreased from 0.11 to 0.04 (with a total fraction of 0.07 only). Below the solidus temperature, one can apply the solid state contraction term $\beta_{\text {SOL }}(\%)=100\left(1-\rho_{\text {SOL }} /\right.$ $\left.\rho_{\mathrm{S} 50}\right)$ to estimate the contraction caused by the $\delta \rightarrow \gamma$ transformation, where $\rho_{\mathrm{SOL}}$ and $\rho_{\mathrm{S} 50}$ are the densities at

Table 1. Nominal compositions (in weight $\%$ ) of the studied steels.

\begin{tabular}{lccccccccc}
\hline Steel & $\mathrm{C}$ & $\mathrm{Si}$ & $\mathrm{Mn}$ & $\mathrm{P}$ & $\mathrm{S}$ & $\mathrm{Cr}$ & $\mathrm{Mo}$ & $\mathrm{Ni}$ & $\mathrm{N}$ \\
\hline AISI 304 & 0.04 & 0.50 & 1.50 & 0.030 & 0.010 & 18.00 & 0.30 & 9.2 & 0.04 \\
AISI 316 & 0.04 & 0.50 & 1.50 & 0.030 & 0.010 & 17.00 & 2.60 & 12.0 & 0.04 \\
A320 & 0.43 & 0.24 & 0.88 & 0.008 & 0.027 & 1.01 & 0.23 & 0.2 & 0.05
\end{tabular}

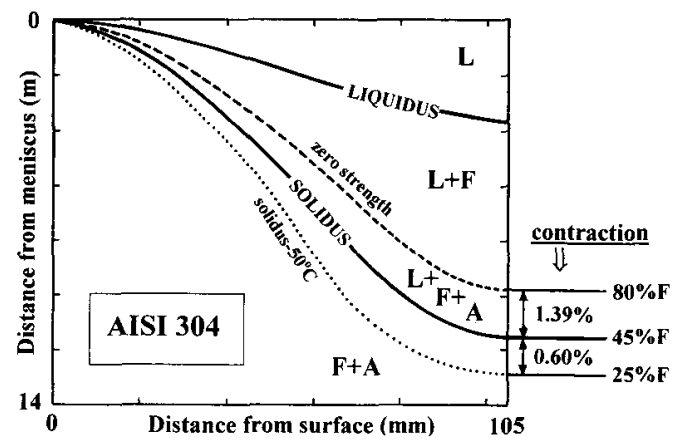

Fig. 1. Calculated phase regions and contraction during solidification of continuously cast AISI 304 slab.

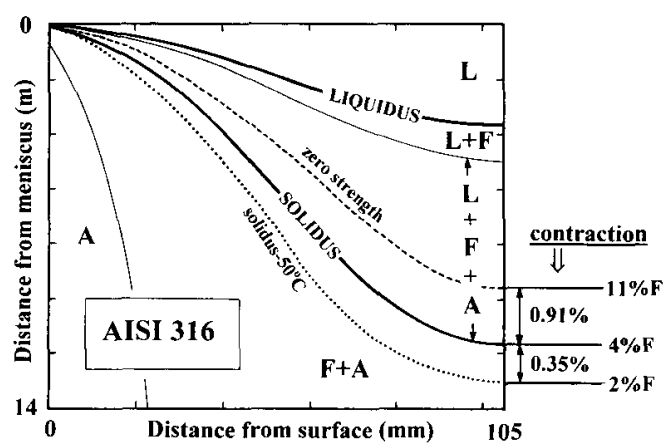

Fig. 2. Calculated phase regions and contraction during solidification of continuously cast AISI 316 slab. the solidus temperature and at a temperature $50^{\circ} \mathrm{C}$ below the solidus. For AISI 304, this gave $\beta_{\text {SOL }}=0.60$ (ferrite fraction reduced with 0.20 ), and for AISI 316 , it gave $\beta_{\text {SoL }}=0.35$ (ferrite fraction reduced with 0.02 only). Consequently, due to the higher shell contraction below the meniscus, AISI 304 may be more sensitive to hot spots and other surface defects than AISI 316.

\subsection{Prediction of Phase, Volume and Hardness Distri- bution in an As-cast Bloom}

Table 2 shows composition profiles measured from an as-cast A320 bloom of Imatra Steel. As can be seen, the profiles are quite uniform except for the slight carbon peak in the center of the bloom. Table 2 also shows the cooling rates of different nodes between 700 and $500^{\circ} \mathrm{C}$ obtained by applying the coupled calculations to the continuous casting process of Imatra, and the grain sizes calculated with the equation of Sec. 2.4. Using the data of Table 2, a phase and a hardness distribution of Fig. 3 was obtained. The as-cast structure contained 13 to $25 \%$ ferrite, 63 to $75 \%$ bainite, 10 to $14 \%$ martensite, and 1 to $2 \%$ rest austenite, and the hardness varied between 300 and $360 \mathrm{HV}$ correlating well with these measured hardness data points. The phase distribution

Table 2. Solute contents (in weight $\%$ ), austenite grain size, and cooling rate at different distances from the surface of a continuously cast A320 bloom.

\begin{tabular}{|c|c|c|c|c|c|c|c|c|}
\hline$x(\mathrm{~mm})$ & $\mathrm{C}$ & $\mathrm{Si}$ & $\mathrm{Mn}$ & $\mathrm{Cr}$ & Mo & $\mathrm{Ni}$ & $\begin{array}{c}d_{\text {GRAIN }} \\
(\mu \mathrm{m})\end{array}$ & $\dot{T}\left({ }^{\circ} \mathrm{C} / \mathrm{s}\right)$ \\
\hline 140 & 0.517 & 0.243 & 0.905 & 1.022 & 0.243 & 0.197 & 2454 & 0.048 \\
\hline 135 & 0.466 & 0.240 & 0.894 & 1.013 & 0.239 & 0.197 & 2454 & 0.048 \\
\hline 128 & 0.395 & 0.236 & 0.878 & 1.001 & 0.233 & 0.196 & 2453 & 0.049 \\
\hline 119 & 0.404 & 0.240 & 0.882 & 1.002 & 0.232 & 0.196 & 2452 & 0.049 \\
\hline 110 & 0.405 & 0.237 & 0.878 & 0.998 & 0.228 & 0.196 & 2451 & 0.050 \\
\hline 100 & 0.406 & 0.234 & 0.873 & 0.993 & 0.223 & 0.196 & 2448 & 0.051 \\
\hline 90 & 0.409 & 0.235 & 0.877 & 0.995 & 0.225 & 0.196 & 2444 & 0.052 \\
\hline 80 & 0.412 & 0.237 & 0.881 & 0.998 & 0.228 & 0.196 & 2437 & 0.054 \\
\hline 70 & 0.415 & 0.238 & 0.885 & 1.000 & 0.230 & 0.196 & 2426 & 0.055 \\
\hline 60 & 0.415 & 0.238 & 0.884 & 1.001 & 0.232 & 0.196 & 2404 & 0.058 \\
\hline 50 & 0.415 & 0.238 & 0.884 & 1.003 & 0.234 & 0.196 & 2361 & 0.060 \\
\hline 40 & 0.415 & 0.238 & 0.883 & 1.004 & 0.236 & 0.196 & 2261 & 0.062 \\
\hline 31 & 0.414 & 0.238 & 0.883 & 1.006 & 0.238 & 0.196 & 2034 & 0.065 \\
\hline 23 & 0.414 & 0.238 & 0.882 & 1.007 & 0.240 & 0.196 & 1666 & 0.067 \\
\hline 17 & 0.414 & 0.238 & 0.882 & 1.008 & 0.241 & 0.196 & 1288 & 0.069 \\
\hline 12 & 0.414 & 0.238 & 0.881 & 1.008 & 0.242 & 0.196 & 1058 & 0.071 \\
\hline 7 & 0.414 & 0.238 & 0.881 & 1.009 & 0.243 & 0.196 & 986 & 0.074 \\
\hline 3 & 0.414 & 0.238 & 0.881 & 1.010 & 0.244 & 0.196 & 980 & 0.076 \\
\hline 0 & 0.414 & 0.238 & 0.881 & 1.010 & 0.244 & 0.196 & 980 & 0.078 \\
\hline
\end{tabular}

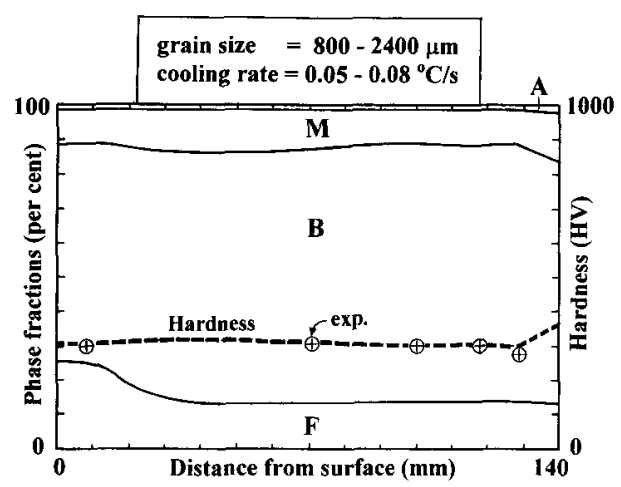

Fig. 3. Calculated phase and hardness distribution at room temperature in an as-cast A320 bloom. 


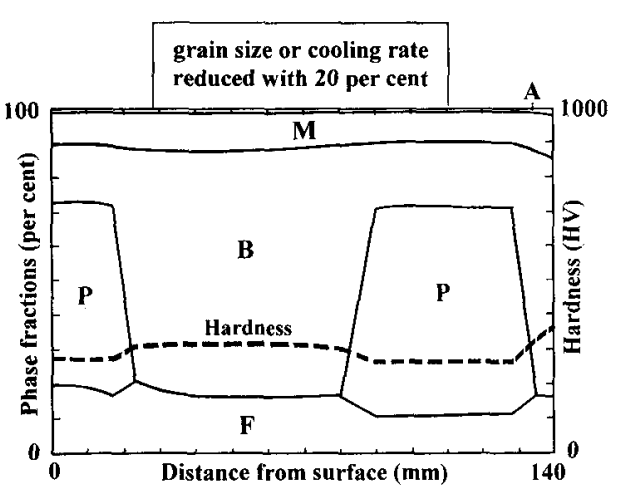

Fig. 4. Calculated phase and hardness distribution at room temperature in an as-cast $\mathrm{A} 320$ bloom using reduced grain size or cooling rate (reduction of $20 \%$ ).

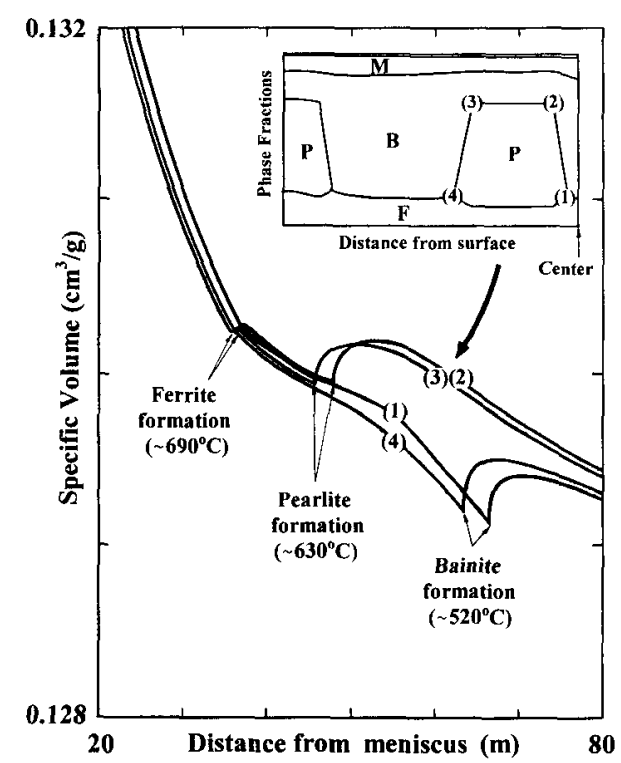

Fig. 5. Calculated volume distribution in certain nodes of a continuously cast $\mathrm{A} 320$ bloom (points are $1=135 \mathrm{~mm}$, $2=128 \mathrm{~mm}, 3=90 \mathrm{~mm}, 4=80 \mathrm{~mm}$ from the strand surface).

is quite uniform: no specific discontinuities were caused by new phases or remarkably changed phase fractions. However, by changing these input data slightly (by reducing the original grain size or cooling rate data by only $20 \%$ ), two separate pearlite regions were formed (Fig. 4). This resulted in certain volume changes in the boundaries of the pearlite region as shown in Fig. 5: the region between points 2 and 3 expanded whereas points 1 and 4 around the region did not (at least, not before the bainite formation temperature at $520^{\circ} \mathrm{C}$ ). Consequently, tensions are formed in regions 1 and 4 which may cause cracks during the cooling process. The present example clearly shows the sensitivity of the input parameters of Table 2 to the results: with slight changes of parameters, a certain transformation "nose" may scarcely be passed resulting in a totally different phase and volume distribution in the bloom.

\section{Conclusions}

Two earlier developed models, a heat transfer model and a thermodynamic-kinetic phase transformation model were coupled to predict the temperature, phase, volume and hardness distribution in a continuously cast strand. The calculation procedures were not fully coupled, because the material properties for the heat transfer model were calculated using mean cooling rates of the strand. A closer coupling of calculations will be made in the future. Some test calculations were presented for two stainless steel slabs showing that due to the higher shell contraction below the meniscus, AISI 304 could be more sensitive to surface defects than AISI 316. The model was also used for the prediction of phase, volume and hardness distribution in an as-cast bloom of Imatra Steel. The phase distribution was not measured experimentally but the calculated hardness data correlated well with the measured hardness values through the bloom. The work will be continued.

\section{Acknowledgement}

The authors wish to thank Mr. Tenho Hätönen of Imatra Steel for kind cooperation and fruitful discussions.

\section{REFERENCES}

1) S. Louhenkilpi: Simulation and Control of Heat Transfer in Continuous Casting of Steel, Doctoral Thesis, Helsinki University of Technology, Finland, (1995).

2) J. Miettinen: Metall. Trans. A, 23A (1992), 1155.

3) J. Miettinen: Report TKK-V-B107, Helsinki University of Technology, Finland, (1995).

4) J. Miettinen and S. Louhenkilpi: Metall. Mater. Trans. B, 25B (1994), 909.

5) J. Miettinen: Report TKK-V-B113, Helsinki University of Technology, Finland, (1995).

6) J. Miettinen: Report TKK-V-B112, Helsinki University of Technology, Finland, (1995).

7) J. B. Gilmour, G. R. Purdy and J. S. Kirkaldy: Metall. Trans., 3A (1972), 1455.

8) K. Hashiguchi, J. S. Kirkaldy, P. Fukuzumi and V. Pavaskar: Calphad, 8 (1984), 173.

9) M. Enomoto: ISIJ Int., 32 (1992), 297.

10) F. Wever, A. Rose, W. Peter, W. Strassburg and L. Rademacher: Atlas zur Wärmebehandlung der Stähle, Verlag Stahleisen m.b.H., Düssseldorf, (1961).

11) A. Rose and H. Hougardy: Atlas zur Wärmebehandlung der Stähle, Vol. 2, Verlag Stahleisen m.b.H., Düssseldorf, (1972).

12) Atlas of Continuous Cooling Transformation Diagrams for Engineering Steel, ed. by British Steel Corporation, Sheffield, (1977).

13) J. Miettinen: Comparison of Phase Transformation Calculations with Experimental Results, Helsinki University of Technology, Finland, Unpublished Research, (1996).

14) A. Jablonka, K. Harste and K. Schwerdtfeger: Steel Res., 62 (1991), 24

15) A. Suzuki, T. Suzuki, Y. Nakaoka and Y. Iawata: J. Jpn. Inst. Met., 32 (1968), 1301

16) M. Sugiyama, T. Umeda and T. Matsuyama: Tetsu-to-Hagané, 60 (1974), 1094.

17) K. Yasumoto, T. Nagamichi, Y. Maehara and K. Gunji: Tetsu-to-Hagané, 73 (1989), 14. 